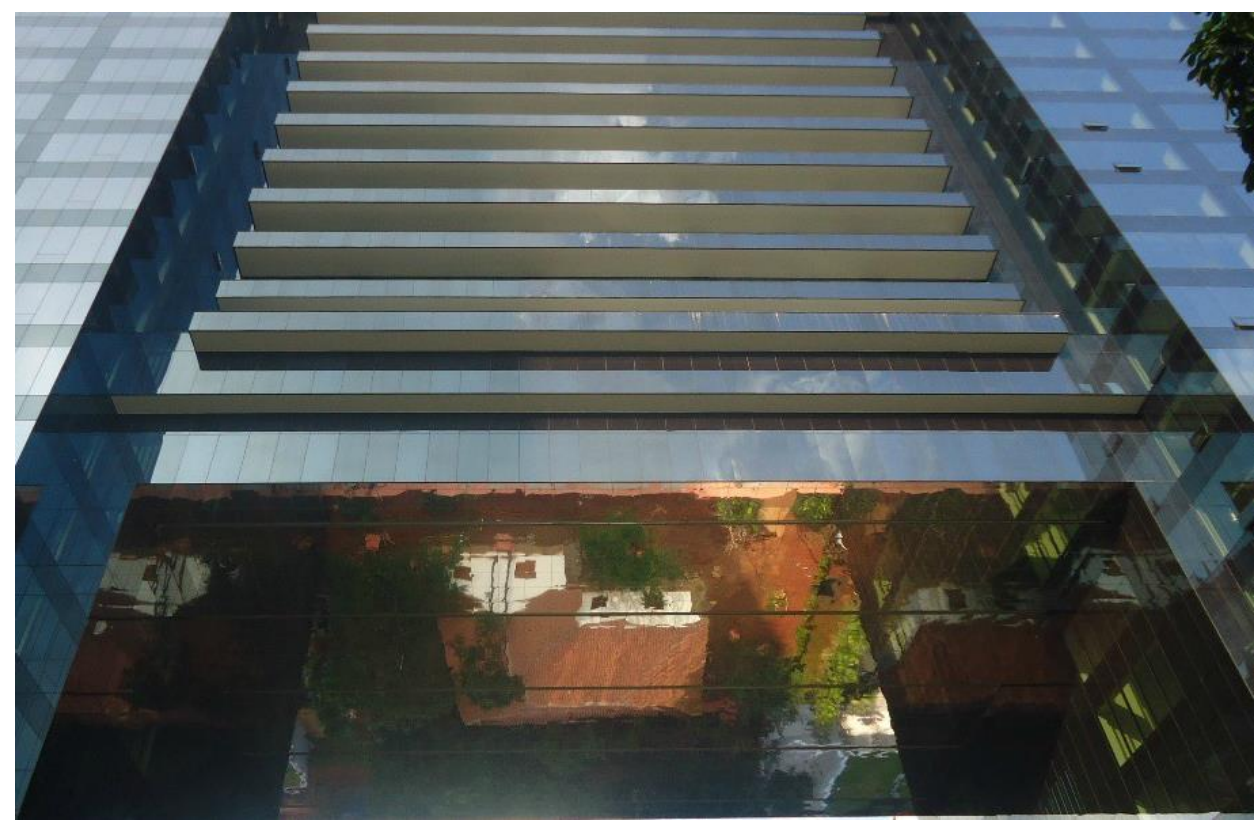

\title{
Análise do discurso da arqueologia preventiva na Folha de S. Paulo: A Casa Bandeirista do Itaim
}

Discourse analysis of the preventive archeology in Folha de S. Paulo: the Casa Bandeirista do Itaim

\author{
Glória Tega ${ }^{1}$ \\ Rodrigo Bastos Cunha ${ }^{2}$
}

\section{Resumo:}

Com o referencial teórico a Análise do Discurso de linha francesa, este trabalho analisa matérias publicadas no jornal Folha de S. Paulo sobre pesquisas arqueológicas realizadas para o licenciamento de obras, especialmente textos que fazem referência ao caso da Casa Bandeirista do Itaim, São Paulo/SP. O efeito de sentido gerado nas matérias da Folha analisadas é ligado a uma Arqueologia praticada em lugares remotos, sendo que a Arqueologia preventiva, como a do caso da Casa Bandeirista, não aparece nos textos da Folha com força de ciência.

Palavras-chave: Análise do Discurso; Arqueologia; Arqueologia Preventiva; Casa Bandeirista; Jornalismo.

\section{Abstract:}

With the theoretical Discourse Analysis of French Line, this paper analyzes the material published in the Folha de S. Paul on archaeological research conducted for the licensing works, especially those texts that refer to the case of the House Bandeirista Itaim, Sao Paulo / SP. The effect of meaning generated in the field of sheet is connected to an archeology practiced in remote places, and the preventive archeology not appear in the texts of science sheet strength.

Keywords: Discourse Analysis; Archaeology, Archaeology Preventive,; Bandeirista House, Journalism.

\footnotetext{
${ }^{1}$ Jornalista (PUC- Campinas), Especialista em Divulgação Científica (ECA/USP) Mestre em Divulgação Científica e Cultural (LABJOR/UNICAMP).E-mail: gloriatega@uol.com.br

${ }^{2}$ Linguista (UNICAMP), especialista em Jornalismo Científico (UNICAMP), mestre em Comunicação Social (UMESP) e doutor em Linguística Aplicada (UNICAMP). Pesquisador (LABJOR/UNICAMP) e professor credenciado junto aos cursos de pós-graduação Lato Sensu em jornalismo científico e junto ao programa do mestrado em divulgação científica e cultural, ambos da Universidade Estadual de Campinas (UNICAMP). E-mail: rbcunha@unicamp.br
} 


\section{Apresentação}

Este artigo tem como objetivo apresentar uma análise de reportagens publicadas no jornal Folha de S. Paulo sobre um caso específico de arqueologia preventiva, o da Casa Bandeirista do Itaim, na capital paulista. A arqueologia preventiva, realizada por empresas privadas para o licenciamento de obras, éndistinta da arqueologia acadêmica, feita tradicionalmente pelas universidades. A análise aqui apresentada éiparte de uma pesquisa mais ampla desenvolvida no mestrado sob a ótica da linha francesa da Análise do Discurso e concluída em $2012^{3}$.

\section{O crescimento da Arqueologia no Brasil a partir da portaria 230 do IPHAN}

A implantação da Portaria 230 do Instituto de Patrimônio Histórico e Artístico Nacional (IPHAN), em dezembro de 2002, passou a exigir que o licenciamento ambiental, como requisito para a realização de obras, contemplasse também a pesquisa a respeito de nossas heranças culturais e de nossas origens, descobertas por meio da pesquisa arqueológica. A medida acabou impulsionando um grande crescimento no que diz respeito a essas pesquisas no Brasil; gerou a criação de empresas especializadas na realização dos licenciamentos de obras; as Universidades também passaram a se adequar para poderem, assim como as empresas privadas, realizar os licenciamentos; a demanda por profissionais arqueólogos aumentou; foram criados cursos de graduação em Arqueologia, anteriormente apenas um curso de pós-graduação (Mestrado e Doutorado) feito por graduados em História, Geologia, Antropologia ou outras áreas do conhecimento. Enfim, a Arqueologia no Brasil ampliou sua atuação, as pesquisas ganharam espaço dentro e fora das Universidades e, assim, se configurou um mercado de atuação, de trabalho, o campo da Arqueologia.

A citada Portaria, além de exigir as pesquisas arqueológicas antes e durante a execução das obras, estabeleceu também que a sociedade deveria ser compensada por possíveis danos causados ao patrimônio arqueológico - no Brasil, configurado como um bem público, sob a tutela da União, segundo a Constituição do Brasil de 1988 -, e com isso, medidas que visam a um retorno à sociedade dos resultados obtidos nas pesquisas se tornaram obrigatórias com sua entrada em vigor. Assim, a Arqueologia passou a ser mais evidente, chegou à população em forma de palestras, cartilhas escolares, cursos

\footnotetext{
${ }^{3}$ CALIPPO, G. M. V. “Arqueologia em notícia: pesquisas impressas, sentidos circulantes e memórias descobertas”. Campinas (SP): IEL/Labjor, 2012 (dissertação de mestrado).
} 
diversos, visitas guiadas aos sítios, museus criados para a exposição da cultura material proveniente de pesquisas realizadas para licenciamentos ${ }^{4}$, dentre muitas outras ações que ajudaram a disseminar essa ciência, o que exigiu o envolvimento de profissionais de diversas áreas tais como Educação, Museologia, Turismo, Comunicação, e, de outro lado, acabou por envolver os arqueólogos com processos educativos, museológicos, de turismo, de comunicação e até de marketing. Boa parte desses processos foi aprendida e ainda se aprende na prática, mas muito do que foi feito desde a implantação da Portaria já se tornou tema de monografias, dissertações e teses, realizadas em programas de graduação e pós-graduação da própria Arqueologia e também das diversas áreas envolvidas - Educação, Museologia, Turismo, Comunicação, entre outras.

Porém, é possível verificar uma lacuna em todo esse processo, que já dura mais de 10 anos: como funciona a comunicação da Arqueologia feita pelos meios de comunicação de massa, mais precisamente a imprensa? O que é divulgado? De que maneira? Como os leitores são incitados a entender Arqueologia?

\section{Seleção do corpus}

Na pesquisa geral desenvolvida no mestrado, escolheu-se a Folha de S. Paulo para essa análise por ser o jornal de maior circulação do país, por abordar temas de âmbito nacional, como a arqueologia praticada na Amazônia, por exemplo, e por tematizar questões locais do estado de São Paulo, mas especificamente, da capital paulista, como a arqueologia praticada em um ambiente urbano, no caso da Casa Bandeirista do Itaim.

O ponto de partida foi uma análise de matérias sobre Arqueologia publicadas entre 2000 e 2010, para contemplar um período anterior àdpublicação da Portaria 230 do IPHAN e um período posterior em que fosse possível confrontar o número de publicações sobre Arqueologia no jornal com o número de portarias de autorização de obras emitidas pelo IPHAN, a partir dos levantamentos realizados por Zanettini (2009) e Wichers (2010). Após esse gesto de análise, chegou-se a uma seleção de textos a serem analisados mais profundamente, os quais foram divididos em cinco grupos temáticos: 1- a pesquisa arqueológica acadêmica sobre a ocupação da Amazônia; 2- a pesquisa arqueológica preventiva para licenciamento de obra na Casa Bandeirista Itaim; 3- a discussão sobre a Portaria 230 do IPHAN e suas consequências; 4- o mercado de trabalho em Arqueologia e a imagem do arqueólogo; 5- a Arqueologia subaquática, pesquisa realizada embaixo

\footnotetext{
${ }^{4} \mathrm{O}$ Museu Água Vermelha, em Ouroeste - SP, é um exemplo.
} 
d'água (como a que envolve navios naufragados no fundo do mar, por exemplo). Apresentaremos aqui uma análise de matérias do segundo grupo, sobre a Casa Bandeirista Itaim.

$\mathrm{Na}$ análise mais aprofundada dos textos, mobilizamos noções e conceitos da Análise do Discurso de linha francesa com os objetivos de examinar os traços das condições de produção presentes nos discursos (cf. ORLANDI, 2008; ORLANDI, 2010); apurar quais são as vozes presentes nos textos jornalísticos (a polifonia ou heterogeneidade do discurso, cf. ZAMBONI, 1997; AUTHIER-REVUZ, 2008); averiguar a presença de memórias discursivas (cf. ORLANDI, 2008); verificar o funcionamento do mecanismo de antecipação que gera determinados efeitos de sentido em seus leitores (cf. ORLANDI, 2009); encontrar traços de relações de forças por meio de discursos relatados (cf. ORLANDI, 2007) e observar como eles funcionariam como artifícios que autenticam relatos jornalísticos, produzindo a falsa ideia de que esses relatos seriam transmissores imparciais da verdade; e descrever como os verbos dicendi são utilizados para articular o discurso jornalístico com o discurso relatado, gerando efeitos de sentidos (cf. MAINGUENEAU, 1997).

\section{A Casa Bandeirista do Itaim Bibi}

No período analisado, o estado de São Paulo é aquele com o maior número de matérias sobre pesquisas arqueológicas realizadas em seu território: são 63, ou seja, 35\% de todas as matérias publicadas sobre Arqueologia no período de 2000 a 2010 na Folha de S. Paulo. Como cerca de 68\% das matérias selecionadas para São Paulo foram geradas a partir de pesquisas para o licenciamento de obras, optamos por escolher matérias com esse cunho sobre alguma pesquisa realizada em São Paulo. Assim, neste artigo, trataremos das matérias que abordam o sítio arqueológico "Casa Bandeirista do Itaim Bibi”.

A Casa Bandeirista do Itaim Bibi surgiu, então, como uma oportunidade de abordagem de aspectos da própria prática arqueológica, além dos aspectos do discurso sobre ela que forem pertinentes para a Análise do Discurso.

A Casa Bandeirista do Itaim Bibi está localizada na região oeste da cidade de São Paulo, em plena Avenida Faria Lima, um dos metros quadrados mais disputados e, portanto, mais caros da cidade. De acordo com Zanettini (2005), o prédio foi construído no início do século XVII para ser a casa de um fazendeiro, mas acabou tendo diversas funções ao longo do tempo: no século XIX, era sede da Fazenda Itaim; no início do século 
XX, era um abrigo para órfãs, chamado Santa Maria, e, de 1922 a 1980, funcionou no local o Sanatório Bela Vista. A casa representa o início da urbanização e o embrião do bairro Itaim Bibi, pois é o único edifício sobrevivente da então Fazenda Bela Vista que, loteada, deu origem ao bairro.

A construção é uma casa bandeirista, um estilo arquitetônico da época dos bandeirantes, tombada em 1982 pelo Conselho de Defesa do Patrimônio Histórico Arqueológico Artístico e Turístico - CONDEPHAAT -, e o local teve sua primeira abordagem arqueológica em 1988 (ZANETTINI, 2005).

Em 2009 foram feitos a prospecção e o resgate do sítio como parte do licenciamento para a obra de um edifício no local, embora o empreendimento já tivesse se iniciado e causado grande impacto sobre o sítio. Porém, esse sítio já era conhecido e, antes disso, já haviam sido realizadas escavações desde 1988. Foram, dessa maneira, recuperadas 18 mil peças, entre elas fragmentos de cerâmica, vidro, metal, frascos de medicamentos, ossos, além de estruturas do antigo sanatório (ZANETTINI, 2005).

A tabela abaixo reúne as matérias publicadas na Folha a respeito das pesquisas realizadas no sítio arqueológico histórico "Casa Bandeirista do Itaim Bibi”:

Matérias sobre Arqueologia preventiva - Casa Bandeirista do Itaim

\begin{tabular}{|c|c|c|}
\hline Titulo & Data & Onde foi publicada? \\
\hline "Ex-casa" não tem parede, não tem mais nada & $25 / 01 / 2008$ & Caderno Cotidiano \\
\hline Justiça barra obra ao lado de ruína histórica & $29 / 04 / 2009$ & Caderno Cotidiano \\
\hline Construtora afirma que projeto é legal & $29 / 04 / 2009$ & Caderno Cotidiano \\
\hline Construtora continua obra em ruína histórica de SP & $07 / 05 / 2009$ & Caderno Cotidiano \\
\hline
\end{tabular}

\section{A pré-destruição}

A primeira matéria, “'Ex-casa' não tem parede, não tem mais nada”, já anunciava a destruição do sítio Itaim Bibi por motivo de abandono. Veja o seguinte trecho: 
A polifonia (cf. AUTHIER-REVUZ, 2011) é uma característica da matéria, porém ela aparece no texto por meio apenas de discursos indiretos. Observe:

Em dezembro, Teófilo Rocha, diretor da empresa que administra o terreno, afirmou que as obras de restauro começariam no dia 15 de janeiro. A reportagem visitou o local, mas não há sinal de obras. $\mathrm{O}$ diretor foi procurado durante as duas últimas semanas, mas não atendeu à Folha.

A arquiteta Helena Saia, responsável pelo restauro, disse que está sendo feito o orçamento e que a obra começará em fevereiro.

No trecho reproduzido acima, o verbo "afirmar", para se referir ao discurso de Teófilo Rocha, de acordo com CHAROLLES (1976), confere um valor de verdade ao enunciado citado (). Mas, ao relatar que procurou o local e não encontrou obras, e que, depois disso, o diretor não atendeu ao repórter, e, ainda, ao colocar o discurso da arquiteta responsável pelo restauro logo em seguida, dizendo que as obras começariam em fevereiro, há um efeito de sentido de dúvida em relação à verdade atribuída ao discurso do diretor da empresa e da própria arquiteta Helena.

\section{A destruição}

São as três matérias seguintes que tratam da destruição do sítio arqueológico por uma obra no local, em 2009. A notícia, ou o que a Folha chama de "puro registro dos fatos", dos três textos foi a destruição causada à Casa Bandeirista por um grande empreendimento imobiliário.

Pensando na definição de uma matéria de divulgação científica, ou seja, a "textualização jornalística do discurso científico" (ORLANDI, 2008, p.151), surpreendentemente, nenhuma matéria desse grupo se encaixa nessa definição, apesar de tratar de um assunto diretamente relacionado a pesquisas científicas na área de Arqueologia. A notícia da destruição do sítio arqueológico não seria notícia se antes a área não tivesse sido pesquisada e definida como um sítio arqueológico. Entretanto, o único traço de achados arqueológicos que aparece na matéria está na linha fina, sublinhado no trecho abaixo, mas o repórter atribui esse discurso ao Ministério Público e a própria Arqueologia está silenciada aqui (cf. ORLANDI, 1992). Observe: 
Como o discurso do Ministério Público sobre a obra faz parte das condições de produção do discurso jornalístico, buscamos a liminar emitida pela $12^{\mathrm{a}}$ Vara Federal $^{5}$ para confrontar com a matéria da Folha. Nela, porém não há qualquer menção aos objetos encontrados no local. O autor usa o modalizador "segundo o" para indicar que está se apoiando em outro discurso, o do Ministério Público Federal, mas esse discurso não vem da fonte aparentemente consultada para a matéria, a liminar emitida pelo órgão. Como não há nenhum discurso direto (entre aspas) relatado na matéria, não há como saber se alguém do Ministério Público foi entrevistado. A informação sobre o tipo de vestígio arqueológico encontrado no terreno teria vindo de um discurso científico, silenciado no discurso jornalístico, e que serviu de fonte para o Ministério Público emitir a liminar - a pessoa que vistoriou a área? Ou teria vindo do próprio relatório da vistoria, realizada antes da emissão da liminar?

De fato, a liminar do Ministério Público Federal é a voz mais presente no discurso jornalístico. A força que essa fonte exerce é determinante para que o repórter construa seu discurso, sendo sempre presente o uso do discurso relatado direto ou indireto. No exemplo abaixo, o jornalista apoia-se na força que tem um discurso indireto atribuído a uma juíza federal.

(...) a juíza Elizabeth Leão determinou que a obra não prossiga até que a construtora apresente perícia identificando os eventuais danos ao patrimônio arqueológico já causados no local.

Não há discursos citados de cientistas, tampouco a relação do fato noticiado, o embargo da obra, com questões relativas à pesquisa arqueológica. Apesar da liminar consultada pelo repórter citar o Museu de Arqueologia e Etnologia da USP como órgão que informou o IPHAN, em 2008, que as obras no local iniciaram-se sem a pesquisa arqueológica prévia estipulada pela legislação federal, o jornalista não se apoiou em nenhuma fonte ligada ao museu. Observe o trecho da matéria:

Protegido por lei federal, o terreno onde foi instalado o canteiro de obras destinado a levantar uma torre comercial e construir uma praça faz parte do entorno do sítio Itaim, uma construção do século 19, hoje em ruínas, que foi tombada pelos patrimônios históricos do Estado e do município.

Ao consultar a liminar do Ministério Público, é possível perceber os traços dela no discurso jornalístico da reportagem. Observe como esses dois fragmentos são semelhantes:

\footnotetext{
${ }^{5}$ PROCESSO No 2009.61.00.009494-1 Disponível em http://csp.jfsp.jus.br/csp/consulta/consinternetpro1b.csp?nromovimento=2 ,
} 
(...) o denominado Sítio Itaim, que contém a Casa do Itaim-Bibi, imóvel bandeirista é um sitio arqueológico tombado pelo CONDEPHAT e CONPRESP, órgãos estadual e municipal de patrimônio histórico.(...) o imóvel objeto desta ação configura monumento arqueológico , nos termos dos artigos $2^{\circ}$ e $3^{\circ}$, ambos da Lei $n^{\circ} 3.924 / 61(\ldots)$

Além do repórter se apoiar no documento oficial emitido por órgão federal para construir seu discurso, os discursos citados presentes no texto são de membros da construtora responsável pela obra e o jornalista opta por eles para dar voz ao outro lado da notícia, medida recomendada no manual da Folha.

Desse modo, o texto "Construtora afirma que projeto é legal", box da matéria “Justiça barra obra ao lado de ruína histórica”, é construído exatamente por meio desses discursos. Assim, o lugar de onde a pessoa fala, seja uma incorporadora, seja um órgão oficial, está ligado a seus interesses. Naquele texto havia um não especialista sugerindo que a licença poderia ser exigida só para bairros como o centro histórico. Nesse texto, a incorporadora fala que o projeto é legal. Essa afirmação pode ser tanto reflexo de má fé quanto desconhecimento da legislação federal (ou, até mesmo, do que venha a ser patrimônio arqueológico).

Observe o conteúdo do texto do box na íntegra:

A construtora Brascan informou não ter tomado conhecimento oficialmente da decisão que suspendeu
as obras. Seus representantes se disseram "surpresos", pois o empreendimento "está completamente
legalizado".
"Essa liminar não existe, não tem sentido", disse o diretor superintendente da Brascan, Walter Lafemina.
A empresa nega que os 19 mil metros quadrados do terreno sejam alvo de preservação, mas só os 2.000
metros quadrados do Itaim.
Segundo José de Albuquerque, diretor de incorporação da Brascan, a obra começou a ser feita com toda
a documentação legal e é acompanhada, disse, por órgãos da prefeitura e de preservação.
A empresa nega que a parte já executada das obras tenha prejudicado o patrimônio arqueológico do
entorno do sítio Itaim.
Albuquerque diz que o levantamento do patrimônio arqueológico da área foi pedido em uma reunião
com o Iphan e a Procuradoria "há cerca de dez dias", mas que não era condição para que a construção
prosseguisse.
"Estávamos pesquisando se um estudo semelhante feito nos anos 80 está disponível no Museu de
Arqueologia [da USP]. E, se fosse necessário, iríamos contratar um novo estudo. Era isso que estava
combinado." O Ministério Público Federal nega a existência de um acordo.
Albuquerque disse que, com a inclusão da praça, esse será "um projeto com fins culturais, que iráa
valorizar o sítio [Itaim]".

Várias vozes são percebidas no texto: a voz do próprio jornalista, a voz da construtora Brascan, representada por seus diretores Walter Lafemina e José de Albuquerque, e a voz do Ministério Público Federal. O enunciador, o jornalista, é responsável pela situação de enunciação, mas se exime de responsabilidade quando coloca os discursos diretos em seu texto ou quando usa a modalização do discurso do outro, com os modalizadores "segundo" (José de Albuquerque) e "disse que". 
Assim como nos discursos diretos, a escolha do verbo introdutor dos discursos indiretos é "bastante significativa, pois condiciona a interpretação, dando certo direcionamento ao discurso citado" (MAINGUENEAU, 2008, p.150). O repórter usa o verbo negar para se referir ao que a empresa Brascan tem a dizer sobre o dano ao patrimônio, como pode ser visto nos dois trechos abaixo:

A empresa nega que os 19 mil metros quadrados do terreno sejam alvo de preservação, mas só os 2.000 metros quadrados do Itaim.

A empresa nega que a parte já executada das obras tenha prejudicado o patrimônio arqueológico do entorno do sítio Itaim.

Já na primeira frase do texto, quando o jornalista usa as aspas em "surpresos" e "está completamente legalizado" ele indica que essas palavras não seriam suas, mas sim dos discursos dos representantes da empresa Brascan. Authier-Revuz classifica esse tipo de recurso como uma "não-coincidência do discurso consigo mesmo" (AUTHIERREVUZ, 1998, p. 22).

Para Authier-Revuz (2008), todo discurso é heterogêneo e a marca dessa característica é a presença de várias vozes no interior do discurso (polifonia). Essa heterogeneidade do discurso é dividida em heterogeneidade mostrada - quando traz marcas de outros discursos - e constitutiva - quando constitui o próprio discurso, é a presença inevitável do outro, "onde jogam o interdiscurso e o inconsciente” (ZAMBONI, 1997, p.41). A heterogeneidade mostrada pode ser marcada e não-marcada. A primeira está explicitamente apontada no discurso; a segunda não pode ser visível na superfície do discurso.

A matéria "Justiça barra obra ao lado de ruína histórica" é, como todo discurso, heterogênea e compõe-se, sobretudo, da heterogeneidade mostrada não marcada, ou seja, a ausência das aspas do discurso direto. Contudo, baseia-se, somente, em uma única voz: a liminar do Ministério Público Federal.

No entanto, em abril de 2009, data da publicação da matéria, a Portaria 230 do IPHAN, que exige o licenciamento arqueológico para a realização de obras, independentemente de seu tamanho, como se determina no caso da construção do edifício relatado nos textos, já estava em vigor há mais de seis anos. Apesar de essa matéria ser marcada pela heterogeneidade, o repórter não usou outras fontes a não ser a liminar do Ministério Público Federal e os funcionários da construtora Brascan, para construir seu discurso. 
Quando ele silencia o discurso da Portaria 230 do IPHAN ou de arqueólogos, por exemplo, "há uma declinação política na significação que resulta no silenciamento como forma não de calar, mas de fazer dizer 'uma' coisa, para não deixar dizer 'outras'. Ou seja, o silêncio recorta do dizer. Esta é sua dimensão política” (ORLANDI, 1992, p. 55).

Outro traço de discurso heterogêneo pode ser encontrado na matéria "Construtora continua obra em ruína histórica de SP”, publicada em 07 de maio de 2009, que trata de um acordo firmado entre a construtora Brascan e o Ministério Público Federal. Algumas partes desse texto são muito parecidas com de trechos já anteriormente publicados na matéria "Justiça barra obra ao lado de ruína histórica"; há, assim, um "requentamento" (ORLANDO, 2010, p. 08) dos discursos presentes na matéria. O primeiro dos fragmentos reproduzidos abaixo é parte da matéria "Construtora continua obra em ruína histórica de SP" e o segundo pertence à matéria "Justiça barra obra ao lado de ruína histórica". Observe:

Protegido por lei federal por ser considerado sítio arqueológico, o terreno onde foi instalado o canteiro de obras destinado a levantar uma torre comercial e construir uma praça faz parte do entorno do sítio Itaim, construção do século 19. Atualmente em ruínas, o sítio é tombado pelos patrimônios históricos do Estado e do município.

Protegido por lei federal, o terreno onde foi instalado o canteiro de obras destinado a levantar uma torre comercial e construir uma praça faz parte do entorno do sítio Itaim, uma construção do século 19, hoje em ruínas, que foi tombada pelos patrimônios históricos do Estado e do município.

Outra voz presente nesta matéria é um texto publicado na seção "notícias" do site do Ministério Público Federal ${ }^{6}$, no dia 06 de maio de 2009, um dia antes da matéria publicada na Folha. Buscamos esse texto para tentar descobrir qual era a origem dos discursos presentes nesta matéria.

Lendo o texto do Ministério Público Federal é possível notar que o repórter usou vários trechos dele para construir seu discurso.

O primeiro fragmento abaixo é a reprodução de parte do texto publicado pelo Ministério Público Federal. O segundo corresponde à parte da matéria publicada pela Folha relacionada a esse texto. Em ambos, os grifos são nossos:

\footnotetext{
${ }^{6}$ Disponível em http://noticias.pgr.mpf.mp.br/noticias/noticias-do-site/copy_of_meio-ambiente-epatrimonio-cultural/sitio-itaim-mpf-brascan-company-e-maragogipe-assinam-acordo/?searchterm=Sítio Itaim: MPF/SP, Brascan, Company e Maragogipe assinam acordo
} 
Pelo acordo, as empreendedoras se comprometem a paralisar imediatamente qualquer atividade nas áreas que não foram alteradas pela obra de engenharia, inclusive de varrição do terreno e das reformas na Casa do Itaim-Bibi, até que seja feito o programa de prospecção e salvamento arqueológico, que deve ser contratado em dez dias úteis e devidamente autorizado pelo Instituto do Patrimônio Histórico e Artístico Nacional (Iphan). Esse trabalho deve ser concluído em até 90 dias.

$\mathrm{Na}$ área do terreno onde estão sendo feitas as fundações do empreendimento, de acordo com o compromisso firmado, estão proibidas novas escavações (leia mais abaixo), entretanto estão permitidas obras de contenção das paredes da área escavada, que são obras de segurança.

Além disso, pelo compromisso firmado, Brascan, Company e Maragogipe admitiram que fizeram movimentações de terras no local e reconhecem a necessidade de pesquisa arqueológica para que se possa, posteriormente, fazer um eventual salvamento ou preservação do sítio arqueológico. Caso as empresas descumpram qualquer termo do acordo, terão de pagar multa diária de $\mathrm{R} \$ 50$ mil a ser revertida ao Fundo de Direitos Difusos.

O acordo, que precisa ser ratificado pela Justiça Federal, prevê que a empresa irá contratar estudos de "prospecção e salvamento arqueológico" (recolha de itens de valor arqueológico) em até dez dias. Esse trabalho deve ser autorizado pelo Iphan (órgão federal do patrimônio) e os resultados devem sair em até 3 meses.

A "peritagem arqueológica" (estudo do impacto já causado pelas obras ao patrimônio e estimativa do valor arqueológico do local) deve ser contratada em cinco dias, com prazo de até 4 meses para os resultados. A multa à empresa, em caso de descumprimento do acordo, é de $\mathrm{R} \$ 50$ mil por dia.

As partes sublinhadas são bastante parecidas nos dois discursos; no segundo houve apenas uma adequação de trechos do primeiro para a linguagem jornalística, (Lage, 2005).

Curioso é ver como a Folha coloca um título incoerente com o restante da notícia. O título da matéria diz que a construtora continua obra, mas nem no texto do Ministério Público Federal, nem mesmo no próprio texto da Folha esse título é explicado, não há qualquer menção sobre a continuação da obra: não há discursos citados ou relatos do repórter que dizem isso. Se houvessem, esses recursos poderiam explicar o título "Construtora continua obra em ruína histórica de SP", já que são utilizados no discurso jornalístico para atribuir à imprensa um papel de "transmissora do real”, (GRILLO, 2004, p.111).

A explicação para a ausência desses recursos que comprovariam a informação dada no título pode ser porque o título "é um enunciado produzido posteriormente ao artigo que ele introduz, ele é frequentemente da responsabilidade de um redator diferente daquele que escreveu o artigo" (GRILLO, 2004, p.98). Ou, ainda, o fato de que os títulos “desempenham a função básica de informação do jornal, pois eles são, em muitos casos, o único enunciado que o leitor lê sobre a maioria dos assuntos" (GRILLO, 2004, p.98). 


\section{O que não foi notícia}

Segundo a legislação nacional ${ }^{7}$, por ter impactado um sítio arqueológico - de maneira definitiva, em alguns aspectos -, a construtora responsável pelo empreendimento deve financiar medidas compensatórias proporcionais à destruição que promoveu. A empresa Zanettini Arqueologia, contratada pela construtora para realizar as pesquisas arqueológicas em 2009, sugeriu, em seu "Programa Arqueológico do sítio Casa Bandeirista do Itaim Bibi”, “o desenvolvimento de ações voltadas à socialização e extroversão dos resultados" (ZANETTINI, 2009, p. 215) obtidos com a pesquisa arqueológica realizada na área. Essas ações compreendiam um "Programa de Educação Patrimonial" e a musealização dos bens arqueológicos presentes naquele terreno.

No entanto, o Ministério Público decidiu que, visando à reparação do dano ao patrimônio no terreno da casa bandeirista, as responsáveis pela obra financiarão o "Parque de Museus", localizado na Universidade de São Paulo ${ }^{8}$, que englobará, entre outros, o novo prédio do Museu de Arqueologia e Etnologia da USP, um dos principais centros de pesquisa e ensino de Arqueologia do Brasil.

O que foi acordado nesse termo de compromisso, entretanto, não foi noticiado pela Folha, apesar desse acordo ter sido publicado ${ }^{9}$ pela fonte que a Folha usou para construir os discursos das outras notícias sobre o sítio Itaim, ou seja, o site do Ministério Público Federal. Embora não tenha sido feita uma análise comparativa com mais de um veículo, para ilustrar efeitos de sentido gerados por silenciamentos no discurso veiculado pela Folha, cabe dizer que a informação sobre o acordo que não saiu na Folha foi publicada pelo jornal concorrente, O Estado de S. Paulo, com o título "USP e construtoras assinam acordo para reparar dano ao patrimônio". A matéria publicada pelo Estado, em 26 de novembro de 2010, também tem indícios da voz da matéria do Ministério Público Federal em seu discurso.

\footnotetext{
${ }^{7}$ Portaria ${ }^{\circ} 230$, de 17 de Dezembro de 2002, disponível em http://portal.iphan.gov.br/baixaFcdAnexo.do?id=337, consultado em 06/02/2015.

${ }^{8}$ Informações obtidas no site do Ministério Público Federal em http://noticias.pgr.mpf.mp.br/noticias/noticias-do-site/copy of meio-ambiente-e-patrimoniocultural/cidade-de-sao-paulo-ganhara-parque-na-usp-como-compensacao-por-dano-arqueologico-ao-sitioitaim/, consultado em 02/02/2015.

${ }^{9}$ A fonte usada senpre foi o site do Ministério Público Federal, a notícia sobre o tema foi publicada no referido site com o título "MPF/SP: construtora vai compensar danos arqueológico ao Sítio Itaim".
} 


\section{Conclusão}

Surpreendentemente, nenhuma matéria do Grupo 2- a pesquisa arqueológica preventiva para licenciamento de obra na Casa Bandeirista, selecionado inicialmente para a pesquisa de mestrado citada, se encaixa na definição de uma matéria de divulgação científica, ou seja a não há “textualização jornalística do discurso científico” (ORLANDI, 2008, p.151). Apesar de tratar de um assunto diretamente relacionado a pesquisas científicas na área de arqueologia, as matérias apenas dão voz aos aspectos legais do assunto, já que foram construídas apenas baseadas em uma liminar, e na força que ela tem, que proibia a continuação da obra na área do sítio arqueológico.

Não há discursos citados de cientistas, não há relação do fato, o embargo da obra, com questões relativas à pesquisa arqueológica, mesmo considerando-se que a destruição do sítio arqueológico não seria notícia se a área não tivesse sido pesquisada antes e definida como um sítio arqueológico. A Folha noticiou a destruição do sítio e o embargo da obra, todavia, não noticiou o que foi feito para mitigar o impacto causado ao bem cultural.

Dessa maneira, quando o assunto foi a pesquisa arqueológica para o licenciamento de uma obra, no caso o sitio histórico Casa Bandeirista do Itaim Bibi, ficou claro que a Folha não relacionou esse tipo específico de arqueologia preventiva com uma pesquisa científica de arqueologia. Os textos não são típicos de divulgação científica, pois acabam dando voz apenas a aspectos legais do assunto. Eles são heterogêneos, mas foram construídos baseados apenas em documentos escritos: um texto publicado na seção "notícias" do site do Ministério Público Federal e uma liminar emitida pelo Ministério Público Federal. Não há discursos citados de cientistas. Talvez, nesse caso, também permeie a memória coletiva de que a ciência arqueológica seria feita apenas em locais remotos, distante de grandes centros urbanos, e sobre civilizações necessariamente muito antigas - características não observadas no sítio arqueológico histórico Itaim Bibi.

A Folha divulga uma Arqueologia muito aquém daquela praticada no Brasil, o que deixa, dessa maneira, os arqueólogos pouco satisfeitos com as informações científicas que circulam ${ }^{10}$. Por meio dos textos analisados, chegamos à conclusão que partilhamos com o que Cury observou a respeito do público nos museus de Arqueologia: "os

\footnotetext{
${ }^{10}$ Opinião que pode ser constatada no texto "Indiana Jones deve morrer" (ZANETTINI, Paulo Eduardo. Indiana Jones deve morrer. Jornal da Tarde, São Paulo, 18 jul. 1991. Caderno de Sábado, p. 04-05). Em virtude do contato diário com arqueólogos por questões profissionais, somos testemunhas que esse texto ainda é referência para a comunidade de arqueólogos quando o assunto é o que a imprensa divulga sobre Arqueologia.
} 
brasileiros recebem informações superficiais e desconexas ou descontextualizadas; às vezes preconceituosas, importadas e, outras vezes fantasiosas" (CURY, 2006, p. 34).

\section{Referências bibliográficas}

AUTHIER-REVUZ, Jacqueline. Palavras incertas. As não-coincidências do dizer. Campinas, SP: Editora da Unicamp, 1998 . A representação do discurso outro: um campo multiplamente heterogêneo. CALEIDOSCÓPIO. UNISINOS, Vol. 6, n.2, p. 107-119, maio/ago 2008.

Alteridade, dialogismo e Polifonia. Dizer ao outro no já-dito: interferências de alteridades - interlocutiva e interdiscursiva - no coração do dizer. In: LETRAS DE HOJE, vol. 46, n.1, Porto Alegre, jan./mar. 2011, p. 6-20.

CHAROLLES, Michela. Exercices sur les verbes de communication. Pratiques, n. 09, p.83-107, 1976.

CURY, Marília Xavier. Para saber o que o público pensa sobre Arqueologia... . Revista de Arqueologia Pública, São Paulo, n.1., p. 31-48, 2006.

FOLHA DE S. PAULO.. Manual da Redação da Folha de S. Paulo. São Paulo: Publifolha, Ed.16, 2010.

GRILLO, Sheila Vieira de Camargo.j. A produção do real em gêneros do jornalismo impresso. São Paulo: Humanitas, 2004.

IPHAN. Centro Nacional de Arqueologia. 2011. Disponível em:

$<\underline{\text { http://portal.iphan.gov.br/portal/montarPaginaSecao.do?id=15506\&retorno=paginaIph }}$ an>. Acesso em: 17 jul.

LAGE, Nilson. Teoria e técnica do texto jornalístico. Rio de Janeiro: Elsevier, 2005.

MAINGUENEAU, Dominique. Análise de textos de comunicação. 5.ed. São Paulo: Cortez, 2008.

ORLANDI, Eni P.. As formas do silêncio: no movimento dos sentidos. Campinas, SP: Editora da Unicamp, 1992

2007 a. Ed. 7.

. Análise do Discurso: Princípios e Procedimentos. Campinas, SP: Pontes,

. Discurso e texto: formulação e circulação de sentidos. 3 ed. Campinas, SP: Pontes Editores, 2008.

A linguagem e seu funcionamento. As formas do discurso. 5 ed. Campinas, SP: Pontes, 2009.

. Discurso e Textualidade. 2 ed. Campinas, SP: Pontes Editores, 2010.

ORLANDO, Simone Mattos Guimarães. 2010. Clivagens teóricas em torno da categoria "fonte jornalística": considerações a partir das classificações existentes. In: ENCONTRO NACIONAL DE PESQUISADORES EM JORNALISMO, 8., 2010, São Luís: UFM. 
RAMBELLI, Gilson. Arqueologia até debaixo d'água. São Paulo, SP: Maranta, 2002.

WICHERS, Camila Azevedo de Moraes. Museus e antropofagia do patrimônio arqueológico: caminhos da prática brasileira. 483 p. Tese (Doutorado em Museologia) - Departamento de Museologia, Universidade Lusófona de Humanidades e Tecnologias. Lisboa, 2010.

ZAMBONI, Lílian Márcia Simões. Heterogeneidade e subjetividade no discurso da divulgação científica. 211 p. Tese (Doutorado em Linguística) - Universidade Estadual de Campinas. São Paulo, 1997.

ZANETTINI, Paulo Eduardo. 2005. Maloqueiros e seus palácios de barro: O cotidiano doméstico na casa bandeirista. 2005. 413 p. Tese (Doutorado em Arqueologia) - Museu de Arqueologia e Etnologia, Universidade de São Paulo. São Paulo, SP.

Projetar o futuro para a Arqueologia Brasileira: desafio de todos. In:

REVISTA DE ARQUEOLOGIA AMERICANA, n. 27, 2009, p. 71-87, 2009.

ZANETTINI ARQUEOLOGIA. Programa de Salvamento Arqueológico Sítio "Casa Bandeirista do Itaim Bibi”, município de São Paulo, SP. São Paulo. 277p. 2009. 
Para citar essa obra:

TEGA, G. CUNHA, R. B. Análise do discurso da arqueologia preventiva na Folha de S. Paulo: A Casa Bandeirista do Itaim. In: RUA [online]. no. 21. Volume 1, p. 55 - 69 - ISSN 1413-2109. Junho/2015. Consultada no Portal Labeurb - Revista do Laboratório de Estudos Urbanos do Núcleo de Desenvolvimento da Criatividade.

http://www.labeurb.unicamp.br/rua/

Capa: http://www.skyscrapercity.com/showthread.php?t=683880\&page=12

Laboratório de Estudos Urbanos - LABEURB

Núcleo de Desenvolvimento da Criatividade - NUDECRI

Universidade Estadual de Campinas - UNICAMP

http://www.labeurb.unicamp.br/

Endereço:

LABEURB - LABORATÓRIO DE ESTUDOS URBANOS

UNICAMP/COCEN / NUDECRI

CAIXA POSTAL 6166

Campinas/SP - Brasil

CEP 13083-892

Fone/ Fax: (19) 3521-7900

Contato: http://www.labeurb.unicamp.br/contato 